\title{
Enhancing the Capacity of the Mental Health and Substance Use Health Workforce to Meet Population Needs: Insights From a Facilitated Virtual Policy Dialogue
}

Kathleen Leslie ( $\nabla$ kleslie@athabascau.ca )

Athabasca University https://orcid.org/0000-0003-0581-126X

\section{Mary Bartram}

Mental Health Commission of Canada

Jelena Atanackovic

University of Ottawa

Caroline Chamberland-Rowe

University of Ottawa

Christine Tulk

Carleton University

Ivy Bourgeault

University of Ottawa

\section{Research}

Keywords: virtual policy dialogue, knowledge mobilization, stakeholder participation in research, evidence-informed policy, COVID-19

Posted Date: January 18th, 2022

DOI: https://doi.org/10.21203/rs.3.rs-1257859/v1

License: (c) (i) This work is licensed under a Creative Commons Attribution 4.0 International License. Read Full License 


\section{Abstract}

Background: Timely knowledge mobilization has become increasingly critical during the COVID-19 pandemic and complicated by the need to establish or maintain lines of communication between researchers and decision-makers virtually. Our recent pan-Canadian research study on the mental health and substance use health (MHSUH) workforce during the pandemic identified key policy barriers impacting this essential workforce. To bridge the evidence-policy gap in addressing these barriers, we held a facilitated virtual policy dialogue. This paper discusses the insights generated at this virtual policy dialogue and highlights how this integrated knowledge mobilization strategy can help drive evidencebased policy.

Methods: We held a three-hour virtual policy dialogue with 46 stakeholders and policy-decision makers as the final phase in our year-long mixed-methods research study. The event was part of our integrated knowledge mobilization strategy and was designed to generate stakeholder-driven policy implications and priority actions based on our research findings. The data collected from the virtual policy dialogue included transcripts from the small group breakout rooms and main sessions, reflective field notes, and the final report from the external facilitator. Coded data were thematically analyzed to inform our understanding of the prioritization of the policy implications and action items.

Results: Facilitated virtual policy dialogues generate rich qualitative insights that guide communityinformed knowledge mobilization strategies and promote evidence-informed policy. Our policy dialogue identified actionable policy recommendations with equity as a cross-cutting theme. Adapting policy dialogues to virtual formats and including technology-assisted facilitation can offer advantages for equitable stakeholder participation, allow for deeper analysis, and help build consensus regarding evidence-based policy priorities.

Conclusions: Our facilitated virtual policy dialogue was a key knowledge mobilization strategy for our research on the capacity of the Canadian MHSUH workforce to respond to the COVID-19 pandemic. Our policy dialogue allowed us to engage a diverse group of MHSUH workforce stakeholders in a meaningful action-oriented way, provided an avenue to get feedback on our research findings, and generated prioritized action items that incorporated the knowledge and experience of these MHSUH workforce stakeholders.

\section{Background}

Timely knowledge mobilization is a growing concern in social science and health research. This has become increasingly critical during the pandemic and complicated by the need to establish or maintain lines of communication between researchers and decision-makers virtually. Our study on the mental health and substance use health (MHSUH) workforce was funded by a rapid COVID-19 grant and illustrates promising practices in timely knowledge mobilization using rich qualitative data from a facilitated virtual policy dialogue. 


\subsection{The capacity of the mental health and substance use health workforce}

The MHSUH workforce is in critical demand. MHSUH needs and concerns have become even more widespread across Canada during the COVID-19 pandemic and may continue to increase through the anticipated echo pandemic, as the lingering impacts of financial stress, social isolation and bereavement take their toll $(1,2)$. While $66 \%$ of Canadians reported excellent or very good mental health in 2019 , this percentage has dropped to $40 \%$ during the pandemic $(3,4)$. Similarly, the prevalence of depression symptoms has significantly increased across the population (from 2-14\%) (3). Substance use has also increased, with one in four Canadians aged 35-54 years and one in five Canadians aged 18-34 years reporting increased alcohol consumption since the pandemic began (4). Further, these MHSUH impacts have disproportionately affected groups with higher risk factors, including women with younger children, people who live alone, people with a previous diagnosis of a mental health or substance use disorder, youth, people who identify as 2SLGBTQ+, and people who have a low income or are unemployed $(3,4)$. The pandemic has also exacerbated the "already problematic gaps in culturally and linguistically appropriate care" (5 p. 969) and disproportionately affected those already facing inequitable access to care $(6,7,8)$.

Exacerbating rising population health needs, health system disruptions during the pandemic have impacted access to MHSUH care $(5,8,9,10)$. One survey revealed that the COVID-19 pandemic disrupted mental health services in $93 \%$ of countries worldwide while the demand for services is increasing (11). Health system responses, such as converting psychiatric inpatient units to COVID-19 units and redeploying MHSUH staff to work in other health care areas, have negatively impacted access to care (2, $12,13)$; these impacts have also been felt in the substance use sector $(6,14)$. One of the key inputs of health system responsiveness to growing MHSUH needs is the availability and accessibility of qualified MHSUH providers. Unfortunately, in the Canadian context, where most MHSUH providers are either privately funded or only partially publicly funded, this sector of the health workforce is generally overlooked in health policy (15).

There is a dearth of data on the MHSUH workforce in Canada relative to comparable countries such as the United States (16). We secured funding from a rapid, targeted mental health COVID grant to begin to address this gap. Our 12-month mixed-methods study included a literature review, pan-Canadian survey of MHSUH providers, and key informant interviews. Our study provides a foundational snapshot of this otherwise hidden workforce, including its capacity to respond to emerging individual, community, and population health needs in Canada. Our results highlight the complex, policy-relevant barriers to increasing the MHSUH workforce's capacity to provide services, including differences across occupations, genders, and funding models. In order to bridge the evidence-policy gap in addressing the needs of this workforce, we held a facilitated virtual policy dialogue as the culminating knowledge mobilization strategy for our research findings.

\subsection{Policy dialogues as a knowledge mobilization strategy}


Policy dialogues constitute an "interactive knowledge-sharing mechanism" and allow research evidence to be brought together with the knowledge and experience of those who will be involved in, or affected by, policymaking on specific high priority issues (17 p. 2). Given our focus on generating actionable policy recommendations, we use the term policy dialogues throughout this paper; however, these processes are also described as deliberative dialogues or stakeholder dialogues. Policy dialogues are versatile strategies to elicit broad input from diverse stakeholders on policy-relevant research evidence and generate targeted policy directions (18). As a knowledge mobilization strategy, such dialogues can be a powerful tool to address complex policy challenges such as those related to mental health policy, allowing for the consideration of empirical evidence alongside the knowledge and experience of stakeholder participants $(19,20)$. As such, policy dialogues are a valuable strategy to help bridge the gap between research evidence and policy.

\section{Methods}

\subsection{Virtual policy dialogue design}

We held a three-hour virtual policy dialogue via Zoom in June 2021 as the final phase in our mixedmethods study on the capacity of the MHSUH workforce in Canada. The event was part of our integrated knowledge mobilization strategy and was designed to generate stakeholder-driven policy implications and priority actions based on our research findings. The objectives of the policy dialogue were to share the key findings of our research, assess and foster consensus regarding the policy implications of these findings, and identify priority action items to move towards evidence-informed policymaking. The format and plan for the policy dialogue were designed by the research team, the study's pan-Canadian expert advisory committee, and an expert facilitator external to the research team, who was hired for the event (see Table 1 for policy dialogue agenda). We incorporated elements of nominal group technique, using XLeap (a digital facilitation software that enables the capture, ranking and prioritization of input from a group of participants) to generate ideas and understand prioritization. Classic nominal group technique involves silent idea generation regarding a particular question, round-robin sharing of ideas, group discussion, and ranking of ideas by individual vote $(21,22)$. The nominal group method differs from the Delphi method, another well-established consensus-building strategy, in its structured, small-group, faceto-face interaction; whereas, the Delphi is premised on anonymous and asynchronous input and feedback (23).

Two weeks before our virtual policy dialogue, in preparation for the event, all participants received an evidence brief of our preliminary study findings on the impact of the pandemic on the capacity of the MSHUH workforce in Canada. Following a research presentation, participants were divided into virtual breakout rooms with six or seven participants in each room. Breakout rooms were pre-assigned to ensure a mix of stakeholder sectors in each group and to allow participants to speak in their preferred language (French or English). In each breakout room, discussion was facilitated by a team member who was familiar with the research study and trained in XLeap, the facilitation software. The small groups were asked to reflect on and discuss the possible policy implications of our research findings (Focus 1). Ideas 
were brainstormed using XLeap and participants were able to see the ideas generated on the screen. Each small group was then asked to collate their ideas as best as possible and identify their top three policy implications.

Following the small group discussion, the external facilitator engaged the whole group in a discussion of the top three policy implications of each group, highlighting the key points, clarifying the possible policy directions, and creating a synthesized list of the ideas generated. These ideas were then individually ranked by participants using XLeap to determine which policy directions were considered the highest priority. The same process was followed to identify and prioritize key action items and next steps based on the identified policy implications (Focus 2).

With some adaptation, our virtual policy dialogue retained most features of established in-person policy dialogue practices. According to Boyko et al. (25), deliberative stakeholder dialogues have three defining features: a constructive meeting environment, a purposeful mix of participants, and the appropriate use of research evidence. Addressing a high priority issue, pre-circulating a policy brief, skilled facilitation, not attributing comments to individuals (Chatham House Rule), not emphasizing a need for consensus, and follow-up activities to support actions are also features contributing to the success of policy dialogues $(17 ; 26)$. These and other elements were synthesized by Damani et al. (18) in their article on an in-person policy roundtable. Drawing on their work, we have compared our facilitated virtual policy dialogue to these key features and guiding principles in Table 2. The one significant difference was that our dialogue explicitly built toward consensus. In a virtual environment, with less time and space for generative discussion, a technology-assisted and facilitated priority setting activity helped to drive the discussion toward a more concrete outcome.

\subsection{Participants}

We invited participants to attend the policy dialogue based on their knowledge of and interest in the MHSUH workforce. Our research study was guided by a pan-Canadian expert advisory committee composed of knowledge users and collaborating organizations; members of this committee were invited to the policy dialogue and asked to identify further possible attendees. During our qualitative stakeholder interviews, we told participants about the policy dialogue and asked if they had suggestions of others we should invite. We directed our invitations to senior leaders in government departments and organizations, asking them to suggest delegates if they could not attend.

We prioritized inviting a diversity of stakeholder perspectives as much as was feasible, including across organizational sector, occupation, lived experience, geographic region of Canada, and ethno-racial and Indigenous identity. A total of 46 stakeholders representing a variety of sectors from across Canada attended the virtual policy dialogue (see Table 3 for a profile of stakeholder attendees). The policy dialogue followed Chatham House Rule; thus, we are not reporting any identifying information beyond the organizational sector of each participant.

\subsection{Ethics}


This research study was approved by the research ethics boards at the University of Ottawa and Athabasca University. Written online consent forms were provided to all participants in advance of the policy dialogue and the link was provided in the Zoom chat at the beginning of the meeting for anyone who had not yet completed the form. A recording prompt on Zoom required participants to consent to the recording to remain in the online meeting room.

\subsection{Data collection and analysis}

Data generated from policy dialogues come from purposeful conversations where contributors collectively create new understandings by complementing research evidence with their own experiences and knowledge on a particular issue (20). The data collected from the virtual policy dialogue included the full transcripts from each small group discussion and the main sessions, reflective field notes from the research team members who facilitated the breakout rooms, and the final report from the external facilitator. This final report captured all the ideas entered on the XLeap platform in the small groups and the synthesized and prioritized ideas from the main sessions. Audio recordings from the main session and breakout rooms were transcribed verbatim and coded using NVivo.

Studies using policy or deliberative dialogues are unique in that the interpretation of research data by the dialogue participants is, in and of itself, a source of primary data (20). We developed an initial (deductive) coding framework based on the preliminary results of our main research study. As Plamandon et al.'s (20) integrated framework for analyzing data from deliberative dialogues suggests, we also used the key messages identified as policy dialogue participants engaged with our research as further (inductive) codes for categorizing emerging data from the policy dialogue. Coded data were thematically analyzed to identify key concepts raised in the small group breakout rooms and in the plenary sessions. Coding and thematic analyses were regularly discussed and shared among the research team for feedback and consensus.

\section{Findings}

In both the pre-circulated research brief and the research team's presentation at the beginning of the policy dialogue, we presented a synthesis of evidence from our year-long mixed-methods research study that included an extensive literature review, a pan-Canadian MHSUH provider survey, and key stakeholder interviews. The main findings of this study are presented elsewhere $(15,27,28)$. A summary of the key research findings discussed in the facilitated virtual policy dialogue is presented in textbox 1 . 


\section{Textbox 1: Key research findings discussed in facilitated virtual policy dialogue}

- We conducted a literature synthesis, a pan-Canadian survey of 2,177 individuals providing MHSUH services, and 18 semi-structured key informant interviews to gain a deeper understanding of the pandemic's impact on the MHSUH workforce

- The literature synthesis included 129 published articles and 280 grey literature sources and identified negative impacts of pandemics and disasters on MHSUH workforce capacity or service provision, specific modifications made by MHSUH workforces to better respond to population health needs during crises, and the impact that gender, race, ethnicity, and other social identities had on MHSUH population needs, service provision, and providers during the COVID-19 pandemic (15).

- Our pan-Canadian survey found an overall decrease in the capacity of the MHSUH workforce during pandemic despite increasing demands, with the impact varying across occupations, genders, and funding models (28)

- Key informant interviewees identified critical challenges in ensuring MHSUH workforce capacity to respond to increasing demand: adapting to virtual service delivery, providing adequate infrastructure and logistics, recognizing hidden MHSUH occupations, reducing the divide between public and private funding for MHSUH services, preventing provider burnout, and addressing workforce data gaps and siloes (28).

\subsection{Policy Dialogue - Implications of Research Findings}

The ranking exercises resulted in 38 potential policy implications of the research findings (Focus 1 of the policy dialogue). Through discussion led by the external facilitator, this list was condensed by collating similar items together and offering participants a chance to respond and discuss individual items. Participants then voted on their top five choices individually and anonymously. The ten top-ranked policy implications are presented in Table 4.

\subsection{Policy Dialogue - Action Items}

Following the discussion and ranking of the policy implications of our research findings, the same process was followed to generate action items based on the identified policy implications, resulting in 42 potential action items. The top 3 priority action items stemming from each small group discussion were collated and discussed in the plenary session by the external facilitator and voted on by participants. The ten top-ranked action items are presented in Table 5.

\subsection{Final actionable policy recommendations}

The thematically analyzed transcripts from the small breakout rooms and large group discussions informed our contextualized understanding of the prioritization of the policy implications and action items. We identified five overarching themes from the policy dialogue, with equity as a cross-cutting theme that permeated the discussion and all five main themes. Using the prioritized lists created from both Focus 1 (policy implications of the research findings) and Focus 2 (action items and next steps), as 
well as the themes identified in the transcripts, we created a synthesized set of actionable policy recommendations that arise from our research findings (see Table 6).

\section{Discussion}

Our facilitated virtual policy dialogue allowed our research team to acquire broad input from a diversity of participating stakeholders and facilitated critical consideration of our research findings. Throughout the small group breakout room discussions, participants were highly engaged and offered thoughtful insight into the policy implications of our research and key action items, generating rich qualitative data to deepen our understanding of these considerations. The strong agreement by stakeholders on the prioritization exercises suggest that these policy recommendations are critical in addressing the capacity concerns we identified in our research on the MHSUH workforce. As the pandemic continues to challenge the health system and the MHSUH workforce, bridging the evidence-policy divide is critically important.

Tailoring the policy dialogue to the virtual format - while necessitated due to COVID-19 travel restrictions and social distancing requirements - offered some key advantages. These included the ease of incorporating the XLeap facilitation software through shared screen functions, pre-assigned breakout rooms, automatic transcription, and the ability to share links for consent forms and websites in the chat. Recordings were easily done on the Zoom platform, replacing the need for note-takers in each breakout session, and all participants needed to consent to the recording to stay in the meeting. The virtual format was also less resource-intensive (time and money) than an in-person event. This allowed for a variety of voices to be more readily mobilized since stakeholders across Canada could attend more easily, overcoming a criticism of in-person events that can be resource intensive and exclusionary (24). The XLeap facilitation software allowed for more structured discussion and made it easy to bring ideas together from the various breakout rooms for plenary discussion and prioritization in a virtual environment. Researchers planning virtual policy dialogues should consider factoring in the costs associated with this or similar software, as well as the costs of engaging an expert external facilitator. The virtual format also allowed us to analyze the rich qualitative data included in the recorded transcripts from each small group breakout room, making for a deeper analysis than would be possible if we only had access to written notes from these groups.

We included as an objective for our policy dialogue to assess and foster consensus regarding the key policy implications and priority action items arising from our research study. We did this through our facilitated prioritization (ranking and voting) exercises, incorporating an adapted nominal group technique as a consensus identification strategy. Each small group's top three ideas (based on the breakout room discussions) for both focus questions were collated into a long list by the expert facilitator, then ranked in order by priority individually using the facilitation software. Generally, research on policy dialogues suggests that participants value not emphasizing the need for consensus since it is unlikely policymakers or stakeholders would commit themselves to a particular solution without further input and processes (17). However, through the prioritization exercises, we were trying to move towards consensus on foundational steps required to move toward evidence-informed policy, an outcome 
possible from knowledge mobilization policy dialogues (18), rather than seeking commitment from stakeholder attendees to specific actions. Building consensus through dialogue can be particularly valuable in the MSHUH context given that there is a broad spectrum of stakeholders and - in Canadian MHSUH policy - accountability is spread across many sectors and levels of government (19). In future policy dialogues, we suggest it may be valuable to phrase this objective as understanding policy implications from the research and developing a consensus-driven list of actionable solutions to address this variation from conventional policy dialogue guidance. Priority setting approaches may be particularly valuable in a virtual setting, where time and the power of in-person connection are constrained. At the same time, participants may feel that priority setting is rushed or forced in a virtual dialogue.

Following the policy dialogue, we held a meeting to develop a call-to-action paper and infographic, building on the priorities and themes identified. We also incorporated these into a webinar conducted as part of the Canadian Health Workforce Network's annual webinar series. Along with more traditional research deliverables of peer-reviewed journal articles and conference presentations, these created a diverse and integrated knowledge translation strategy for our study. Working with stakeholders in this way also allowed us to grow our network for individuals and organizations from across Canada who have knowledge, experience, and interest in the MHSUH workforce and who continue to work with us on our research in this area.

\section{1 Limitations}

Our virtual policy dialogue had some limitations. Despite the advantages of the virtual format, some participants may have been less comfortable with the Zoom video conferencing technology or may have had challenges with access due to Internet connectivity issues. Given the capacity issues that we identified in our study, we also knew many stakeholders would have pandemic-induced fatigue or burnout, including around attending virtual events. We kept the dialogue to three hours with this in mind and offered ways for stakeholders to stay engaged with the research following the policy dialogue. Nevertheless, a full-day event may have generated further discussion and ideas.

We obtained feedback from participants at the end of the virtual policy dialogue via a quick online survey. However, only 11 participants completed this, making the data of limited value. It may have been helpful to send a follow-up survey to assess how participants viewed the virtual policy dialogue process.

Finally, although we made a serious effort to invite a diverse range of stakeholders, we were not able to engage with all potentially impacted MHSUH groups. The resulting interpretations of our research in terms of policy implications and actionable solutions only reflect the views of those who were in the virtual room and are thus constrained by a potential lack of diversity in providers, perspectives, and lived experiences.

\subsection{Future directions}


Adapting conventional in-person policy dialogues to virtual formats may offer researchers a way to engage a greater diversity of voices with study findings. Future studies using facilitated virtual policy dialogues as a knowledge mobilization strategy could incorporate ways to evaluate the process (focusing on the modifications required for virtual formats and how best to promote inclusion and participation) and outcomes (focusing on subsequent engagement by stakeholders with the generated policy recommendations). Our inclusion of an adapted nominal group technique and online facilitation/voting software should be evaluated as an evolution of policy dialogues that potentially allows for more equitable participation by stakeholders and may help foster consensus on next steps.

\section{Conclusions}

Facilitated virtual policy dialogues provide rich qualitative insights that can guide a community-informed knowledge mobilization strategy and promote evidence-informed policy. Our facilitated virtual policy dialogue was a key knowledge mobilization strategy in our mixed-methods study on the capacity of the Canadian MHSUH workforce to respond to the COVID-19 pandemic. As the final phase of our research, this facilitated virtual policy dialogue allowed us to engage a diverse group of MHSUH workforce stakeholders in a meaningful action-oriented way, provided an avenue to get feedback on our research findings, and generated prioritized action items that incorporated the knowledge and experience of these MHSUH workforce stakeholders.

\section{Declarations}

\section{Author contributions:}

All co-authors contributed to the study conceptualization, data collection, and analysis. KL led the original draft preparation and all other co-authors reviewed and edited the manuscript.

\section{Funding:}

This work was supported by a Canadian Institutes for Health Research Operating Grant. The funder had no role in the design of the study, collection, analysis, or interpretation of data, or writing the manuscript.

\section{Availability of data and materials:}

Portions of redacted transcripts may be made available from the corresponding author on reasonable request.

\section{Ethics approval and consent to participate:}

This project received ethical approval from the University of Ottawa and Athabasca University Research Ethics Boards. All participants provided consent to participate.

\section{Competing interests:}


The authors declare that they have no competing interests.

\section{Acknowledgements:}

The authors wish to thank Audrey Kruisselbrink for her research assistance and the policy dialogue participants for their valuable time and contributions.

\section{References}

1. Canadian Mental Health Association. COVID-19 and mental health: Heading off an echo pandemic. 2020. https://cmha.ca/brochure/covid-19-and-mental-health-heading-off-an-echo-pandemic/ Accessed 10 Dec 2021.

2. Mental Health Commission of Canada. COVID-19 and mental health: Policy responses and emerging issues. 2020. https://mentalhealthcommission.ca/resource/covid-19-and-mental-health-policyresponses-and-emerging-issues-preliminary-scan/. Accessed 30 November 2021.

3. Mental Health Commission of Canada. Mental health and substance use during COVID-19: Summary report. 2021. https://mentalhealthcommission.ca/resource/mental-health-and-substance-use-duringcovid-19-summary-report/. Accessed 10 January 2022.

4. Canadian Centre for Substance Abuse. COVID-19 and increased alcohol consumption: NANOS poll summary report. 2020. https://www.ccsa.ca/sites/default/files/2020-04/CCSA-NANOS-AlcoholConsumption-During-COVID-19-Report-2020-en.pdf. Accessed 10 January 2022.

5. Auerbach J, Miller FJ. COVID-19 exposes the Cracks in our already fragile mental health system. AJPH. 2020;110(7):969-70. doi:10.2105/AJPH.2020.305699.

6. Radfar SR, De Jong CA, Farhoudian A, Ebrahimi M, Rafei P, Vahidi M, et al. Reorganization of substance use treatment and harm reduction services during the COVID-19 pandemic: A global survey. Front Psychiatry. 2021;12. https://doi.org/10.3389/fpsyt.2021.639393

7. Sneed RS, Key K, Bailey S, Johnson-Lawrence V. Social and psychological consequences of the COVID-19 pandemic in African-American communities: Lessons from Michigan. Psychol Trauma. 2020;12(5):446-8. doi:10.1037/tra0000881.

8. Yang J, Landrum MB, Zhou L, Busch AB. Disparities in outpatient visits for mental health and/or substance use disorders during the COVID surge and partial reopening in Massachusetts. Gen Hosp Psychiatry. 2020;67:100-6. doi:10.1016/j.genhosppsych.2020.09.004.

9. de Girolamo G, Cerveri G, Clerici M, Monzani E, Spinogatti F, Starace F, et al. Mental health in the coronavirus disease 2019 emergency-The Italian response. JAMA Psychiatry. 2020;77(9):974. doi:10.1001/jamapsychiatry.2020.1276.

10. Rosenberg S, Mendoza J, Tabatabaei-Jafari H, Salvador-Carulla L. International experiences of the active period of COVID-19 - mental health care. Health Policy Technol. 2020;9(4):503-9. doi:10.1016/j.hlpt.2020.08.016. 
11. World Health Organization. COVID-19 disrupting mental health services in most countries, WHO survey. 2020. https://www.who.int/news/item/05-10-2020-covid-19-disrupting-mental-healthservices-in-most-countries-who-survey. Accessed 30 November 2021.

12. Mateos R, Fernández M, Franco M, Sánchez M. COVID-19 in Spain. Coming back to the 'new normality' after 2 months of confinement. Int Psychogeriatr. 2020;32(10):1169-72. doi:10.1017/S1041610220001155.

13. O'Connor K, Wrigley M, Jennings R, Hill M, Niazi A. Mental health impacts of COVID-19 in Ireland and the need for a secondary care mental health service response. Ir J Psychol Med. 2021;38(2):99-107. doi:10.1017/ipm.2020.64.

14. Knopf A. Number of deaths from untreated addiction may rival those from COVID-19. The Brown University Child \& Adolescent Psychopharmacology Update. 2020;22(7):1-4. doi:10.1002/cpu.30504.

15. Atanackovic J, Bartram M, Leslie K, Chamberland-Rowe C, Tulk C, Bourgeault I. What do we know about the capacity of the mental health and substance use health workforce to respond to emerging needs during the COVID-19 pandemic? A literature synthesis. 2021 [Manuscript in preparation].

16. Health Resources \& Service Administration. Workforce projections: Dashboard. 2021. https://data.hrsa.gov/topics/health-workforce/workforce-projections. Accessed 10 December 2021.

17. Lavis JN, Boyko JA, Oxman AD, Lewin S, Fretheim A. SUPPORT tools for evidence-informed health policymaking (STP) 14: Organising and using policy dialogues to support evidence-informed policymaking. Health Res Policy and Syst. 2009;7:S14. https://doi.org/10.1186/1478-4505-7-S1-S14

18. Damani Z, MacKean G, Bohm E, DeMone B, Wright B, Noseworthy T, et al. The use of a policy dialogue to facilitate evidence-informed policy development for improved access to care: The case of the Winnipeg Central Intake Service (WCIS). Health Res Policy Syst. 2016;14(1):78. https://doi.org/10.1186/s12961-016-0149-5

19. Mulvale G, Chodos H, Bartram M, MacKinnon MP, Abud M. Engaging civil society through deliberative dialogue to create the first mental health strategy for Canada: Changing directions, changing lives. Soc Sci Med. 2014;123:262-8. https://doi.org/10.1016/j.socscimed.2014.07.029

20. Plamondon KM, Bottorff JL, Cole DC. Analyzing data generated through deliberative dialogue: Bringing knowledge translation into qualitative analysis. Qual Health Research. 2015;25(11):152939. Available from: https://doi.org/10.1177/1049732315581603

21. Jones J, Hunter D. Consensus methods for medical and health services research. BMJ. 1995;311(7001):376-80. https://doi.org/10.1136/bmj.311.7001.376

22. Humphrey-Murto S, Varpio L, Gonsalves C, Wood TJ. Using consensus group methods such as Delphi and Nominal Group in medical education research. Med Teach. 2017;39(1):14-9. doi:10.1080/0142159X.2017.1245856

23. Khayatzadeh-Mahani A, Wittevrongel K, Petermann L, Graham ID, Zwicker JD. Stakeholders' engagement in co-producing policy-relevant knowledge to facilitate employment for persons with 
developmental disabilities. Health Res Policy and Syst. 2020;18(39):1-17.

https://doi.org/10.1186/s12961-020-00548-2

24. Boyko JA, Lavis JN, Abelson J, Dobbins M, Carter N. Deliberative dialogues as a mechanism for knowledge translation and exchange in health systems decision-making. Soc Sci Med. 2012;75(11):1938-1945. https://doi.org/10.1016/j.socscimed.2012.06.016

25. Boyko JA, Kothari A, Wathen CN. Moving knowledge about family violence into public health policy and practice: a mixed method study of a deliberative dialogue. Health Research Policy and Systems. 2016;14(31). https://doi.org/10.1186/s12961-016-0100-9

26. Lavis JN, Boyko JA, Gauvin FP. Evaluating deliberative dialogues focussed on healthy public policy. BMC Public Health. 2014 Dec;14(1):1287. https://doi.org/10.1186/1471-2458-14-1287

27. Bartram M, Leslie K, Atanackovic J, Chamberland-Rowe C, Tulk C, Bourgeault, I. Bringing the mental health and substance use health workforce into focus: Recommendations from a virtual policy dialogue. 2022 [Manuscript in preparation].

28. Tulk C, Bartram M, Leslie K, Atanackovic J, Chamberland-Rowe C, Bourgeault I. The impact of COVID19 on the mental health and substance use health workforce in Canada. 2022. [Manuscript in preparation].

\section{Tables}


Table 1

Agenda for Virtual Policy Dialogue

\section{Time Activities}

10 Introductions, review agenda, discuss process, conduct consent

minutes

20 Discuss preliminary research findings from the mixed-methods study on MHSUH provider minutes capacity during the pandemic

Focus 1: What are the policy implications of the research findings?

$45 \quad$ Small group breakout room: Brainstorming and discussion minutes

$25 \quad$ Full group discussion: Synthesizing and prioritizing the policy implications minutes

$10 \quad$ Break

minutes

Focus 2: What are the key action items, recommendations, and next steps?

$30 \quad$ Small group breakout room: Brainstorming and discussion

minutes

35 Full group discussion: Synthesizing and prioritizing the key action items, minutes recommendations, and next steps

$5 \quad$ Wrap-up and thank attendees

minutes 
Table 2

Design elements of our facilitated virtual policy dialogue (adapted from Damani et al., (18)).

Design Element Present? Details and Adaptations

Addresses a high-priority policy issue

Clear meeting objectives

Pre-circulated information

package and evidence summaries
Yes

- The capacity of MHSUH providers to address emerging population needs is a high priority national policy issue

Yes

- Policy dialogue objectives were determined in advance and circulated with the invitation and the pre-meeting information package. Objectives were reiterated at the beginning of the policy dialogue verbally and on a shared-screen slide.

Yes $\quad$ Participants were provided with an agenda (see Table 1), slide deck containing synthesized literature review and preliminary study findings, and consent form in advance

- Materials were available in both French and English, Canada's two official languages

Environment conducive to deliberations

Yes

- Policy dialogue facilitated over Zoom using facilitation software (XLeap), shared screens, small breakout rooms facilitated by members of the research team, and an external overarching professional facilitator

- Three-hour meeting scheduled during business

hours across five Canadian time zones

- One breakout room facilitated in French

Clear rules of engagement

Yes

- Chatham House Rule followed

- Experienced facilitator hired to conduct policy dialogue and train research team in breakout room facilitation and software use

Recording of discussions

Yes

Yes

Representation of various stakeholder perspectives

(including researchers and knowledge user partners), including those who may be affected by decisions related to the issue
- Main session and breakout rooms in Zoom were recorded

- Recording prompt on Zoom required participants to provide consent to record to stay in the meeting

- Written consent forms were provided to all participants in advance of the meeting, and the link provided in the chatbox at the start of the meeting

- Participants were purposively selected to represent government, policy, and practitioner stakeholders (see Table 3)

- Stakeholders included a range of MHSUH providers

- Participants were assigned to small group breakout rooms to maximize variation of perspectives

- The research team (including knowledge user partners/advisors) played a key role of discussion group facilitators 
Synthesis of high-quality research Yes evidence

- Synthesis of research findings from literature review, pan-Canadian MHSUH provider survey, and key stakeholder interviews were provided in advance of the policy dialogue and presented at the beginning of the dialogue

Opportunity for discussion

Yes

- Facilitated small group breakout rooms included 5-7 participants using collaborative facilitation software

- Combined, two breakout sessions included over one hour for discussion

No emphasis on reaching

No

consensus

- One of the objectives was to assess and foster 'near' consensus around the priority policy implications (Focus 1) and next steps (Focus 2) of the research findings

- Using an adapted nominal group technique, each group's top three ideas (based on the small group discussion) for both focus questions were collated and synthesized into a long list by the expert facilitator, then ranked by individual participants in order by priority using the facilitation software - With less time and space for generative discussion in a virtual format (versus in-person), this consensus building exercise allowed for more focused and concrete discussion

- The research team clearly communicated that these priorities would help direct next steps, but no commitment to specific actions was expected from participants

Skilled facilitation

Yes

- External expert facilitator (not a stakeholder or part of the research team) hired to facilitate the main session and lead the ranking and voting using software developed for this purpose - Breakout rooms were facilitated by research team members familiar with the subject matter and trained in the use of the software

Outcome evaluation

Limited

- The external expert facilitator provided anonymous post-dialogue evaluation forms to each participant with few completing $(n=11 / 46)$.

Outputs developed and action plan put in place

$\begin{array}{ll}\text { In } & \text { - Critical commentary "call to action" article } \\ \text { progress } & \text { prepared for publication (Bartram et al., 2021) } \\ & \text { - Multiple conference presentations and keynotes } \\ & \text { conducted } \\ & \text { - Infographic developed of research findings } \\ & \text { including insights from policy dialogue } \\ & \text { - Webinar conducted as part of the Canadian } \\ & \text { Health Workforce Network's annual webinar series } \\ & \text { (November 2021) } \\ & \text { - Policy dialogue reflection and follow-up with } \\ & \text { expert advisory group completed (November 2021) }\end{array}$


Table 3

Profile of stakeholder participants attending the policy dialogue

Organizational Sector

Mental health/substance use health organizations

Regulators or professional associations

Mental health or substance use health service provider/organization 8

Government

Other health organization

Academic/research

Lived experience/lived experience advocacy organization

Industry (e.g., employment insurance)

Total

\section{Number of participants}

9

8

8

6

3

2

2

46

Table 4

Ranked policy implications of our research findings (Focus 1)

\begin{tabular}{|c|c|c|}
\hline Rank & Item & Votes \\
\hline $1 *$ & Develop a more diverse and culturally competent workforce. & 31 \\
\hline $1 *$ & Create environments that prevent MHSUH workforce burnout. & 31 \\
\hline 2 & $\begin{array}{l}\text { Collect comprehensive MHSUH workforce data, stratified by race, ethnicity, gender } \\
\text { etc. }\end{array}$ & 26 \\
\hline 3 & Invest in training, recruitment, and regulation. & 25 \\
\hline $4^{*}$ & Achieve funding parity between MHSUH and physical health services. & 22 \\
\hline $4^{*}$ & $\begin{array}{l}\text { Communicate the need to strengthen MHSUH workforce capacity in response to the } \\
\text { pandemic. }\end{array}$ & 22 \\
\hline 5 & Optimize the mix of virtual and in-person delivery to broaden reach. & 21 \\
\hline 6 & Create better policy on interface between public and private sectors. & 16 \\
\hline $7 *$ & Remove barriers to inter-provincial mobility. & 15 \\
\hline $7 *$ & $\begin{array}{l}\text { Value contributions of different roles with the MHSUH workforce, including peer } \\
\text { support. }\end{array}$ & 15 \\
\hline
\end{tabular}

* Tie in ranking with another item 
Table 5

Ranked action items based on policy implications (Focus 2)

\begin{tabular}{|llc|}
\hline Rank & Item & Votes \\
\hline 1 & $\begin{array}{l}\text { Provide full public funding for MHSUH care, including preventative care and care } \\
\text { that addresses inequities. }\end{array}$ & 27 \\
\hline 2 & Collect standardized MHSUH workforce data, including demographic data. & 26 \\
\hline 3 & Develop competencies and tools for culturally appropriate services. & 24 \\
\hline 4 & $\begin{array}{l}\text { Generate better MHSUH workforce data, including unregulated providers, with a } \\
\text { focus on sex/gender, racial, and other equity demographics. }\end{array}$ & 21 \\
\hline 5 & Manage burnout through support, remuneration and integrated care models. & 20 \\
\hline 6 & Increase supply through training, remuneration, and recruiting for diversity. & 16 \\
\hline 7 & Remove regulatory barriers to improve access to quality MHSUH services. & 14 \\
\hline $8^{*}$ & Increase support for community-led interventions. & 12 \\
\hline $8^{*}$ & Adopt promising practices. & 12 \\
\hline 9 & Adopt psychological health and safety standards for the MHSUH workforce. \\
\hline
\end{tabular}

* Tie in ranking with another item 
Table 6

Themes and actionable policy recommendations arising from the facilitated virtual policy dialogue

\begin{tabular}{|c|c|c|}
\hline Theme & $\begin{array}{l}\text { Actionable policy } \\
\text { recommendation }\end{array}$ & $\begin{array}{l}\text { Key points and equity considerations arising from small } \\
\text { group discussions }\end{array}$ \\
\hline Funding & $\begin{array}{l}\text { Increase public investment } \\
\text { in the MHSUH workforce } \\
\text { and promote sectoral } \\
\text { coordination, particularly } \\
\text { between the public and } \\
\text { private sectors }\end{array}$ & $\begin{array}{l}\text { - MHSUH services in Canada are severely underfunded, } \\
\text { creating inequities that significantly impact } \\
\text { marginalized and vulnerable groups: Canada needs to } \\
\text { achieve funding parity between MHSUH services and } \\
\text { physical health services to address these equity issues } \\
\text { - Preventative MHSUH care should be prioritized and } \\
\text { fully funded } \\
\text { - Public investment is required to address the disparity } \\
\text { in remuneration between MHSUH providers (e.g., } \\
\text { between providers in public/private sectors and peer } \\
\text { support workers) } \\
\text { - Public investment in the training and recruitment } \\
\text { pipelines would help address the increasing MHSUH } \\
\text { needs of the population, similar to what some Canadian } \\
\text { jurisdictions have done for personal support workers } \\
\text { - Explicit policy addressing the relationship between the } \\
\text { public and private sectors to create more seamless care, } \\
\text { provide better integration, optimize synergies, and avoid } \\
\text { inefficiencies that result from lack of coordination }\end{array}$ \\
\hline $\begin{array}{l}\text { Regulation } \\
\text { and } \\
\text { recognition }\end{array}$ & $\begin{array}{l}\text { Standardize regulation } \\
\text { across the country to } \\
\text { promote equitable access } \\
\text { to services and remove } \\
\text { barriers to practice, } \\
\text { particularly around inter- } \\
\text { jurisdictional practice and } \\
\text { virtual care }\end{array}$ & $\begin{array}{l}\text { - Regulatory barriers hindering inter-provincial virtual } \\
\text { care and mobility of regulated practitioners need to be } \\
\text { addressed; this would allow the delivery modality } \\
\text { (virtual or in-person) to be optimized, recognizing that } \\
\text { each modality has potential equitable access } \\
\text { implications, and enable the workforce to be where it is } \\
\text { needed with more efficient deployment } \\
\text { - Pandemic has highlighted the importance of } \\
\text { regulation in contributing to equitable access to } \\
\text { services since much public and private funding is } \\
\text { limited to regulated providers } \\
\text { - Focus on promoting collaboration between providers } \\
\text { with complementary scopes of practice to provide } \\
\text { patients with comprehensive MHSUH services }\end{array}$ \\
\hline
\end{tabular}




\begin{tabular}{|c|c|c|}
\hline Theme & $\begin{array}{l}\text { Actionable policy } \\
\text { recommendation }\end{array}$ & $\begin{array}{l}\text { Key points and equity considerations arising from small } \\
\text { group discussions }\end{array}$ \\
\hline $\begin{array}{l}\text { Burnout } \\
\text { and } \\
\text { wellbeing }\end{array}$ & $\begin{array}{l}\text { Create enabling } \\
\text { environments for MHSUH } \\
\text { provider wellbeing and } \\
\text { retention to address } \\
\text { burnout }\end{array}$ & $\begin{array}{l}\text { - Recruitment strategies to increase supply of providers } \\
\text { should include a focus on enhancing the diversity of the } \\
\text { MHSUH workforce } \\
\text { - Learn from experiences of other groups of providers } \\
\text { who have developed or identified promising practices } \\
\text { (e.g., law firms that are identifying metrics contributing } \\
\text { to employee burnout) } \\
\text { - Uniform adoption of standards and positive practices } \\
\text { to improve psychological health and safety of MHSUH } \\
\text { providers in both public and private sectors, including } \\
\text { consideration of unique harms that may occur when } \\
\text { providing virtual services } \\
\text { - The existing peer support community of MHSUH } \\
\text { providers with lived MHSUH experience is hidden due to } \\
\text { stigma, creating lack of access to care and burnout: } \\
\text { MHSUH practitioners should be able to speak freely } \\
\text { about their own MHSUH concerns and seek the support } \\
\text { of peers without fear of being stigmatized }\end{array}$ \\
\hline $\begin{array}{l}\text { Workforce } \\
\text { data }\end{array}$ & $\begin{array}{l}\text { Develop comprehensive } \\
\text { and standardized datasets } \\
\text { describing the MHSUH } \\
\text { workforce for better } \\
\text { workforce planning }\end{array}$ & $\begin{array}{l}\text { - We need a clear definition of what is classified as the } \\
\text { MHSUH workforce because job titles and descriptions } \\
\text { vary across the country } \\
\text { - Data should be collected in a standardized way across } \\
\text { the country to allow for comparison across jurisdictions } \\
\text { and provider groups and contribute to systematic } \\
\text { workforce planning } \\
\text { - Data sharing needs to be established so that data } \\
\text { does not stay in silos } \\
\text { - Data collection challenges are particularly prevalent } \\
\text { for unregulated MHSUH providers } \\
\text { - Better data is required to understand who is in the } \\
\text { MHSUH workforce to allow Canada to stratify its } \\
\text { MHSUH workforce by different identifiers (e.g., race, } \\
\text { ethnicity, and gender): we cannot manage what we do } \\
\text { not measure, and we currently do not measure any of } \\
\text { these diversity or equity demographics of the workforce }\end{array}$ \\
\hline
\end{tabular}




\begin{tabular}{|lll|}
\hline Theme & $\begin{array}{l}\text { Actionable policy } \\
\text { recommendation }\end{array}$ & $\begin{array}{l}\text { Key points and equity considerations arising from small } \\
\text { group discussions }\end{array}$ \\
\hline $\begin{array}{l}\text { Cultural } \\
\text { competence }\end{array}$ & $\begin{array}{l}\text { Equip MHSUH workforce } \\
\text { to provide culturally } \\
\text { appropriate and person- } \\
\text { centred care }\end{array}$ & $\begin{array}{l}\text { - The MHSUH workforce needs to develop the } \\
\text { knowledge, skills, and competencies to address MHSUH } \\
\text { across the continuum of care and services - from } \\
\text { promotion and prevention to treatment of serious and } \\
\text { concurrent illness } \\
\text { - Measuring equity and diversity demographics of the } \\
\text { MHSUH workforce will contribute to building the } \\
\text { capacity of the workforce to provide culturally } \\
\text { appropriate and person-centred care } \\
\text { - More research is needed to identify the barriers to } \\
\text { providing culturally appropriate services and identify } \\
\text { the core competencies required to provide services for a } \\
\text { range of equity-seeking groups, recognizing that } \\
\text { different skills are needed to work with different groups } \\
\text { - Toolkits should be developed to assess MHSUH } \\
\text { service teams to understand whether the range of } \\
\text { competencies are represented and build on skills } \\
\text { already present } \\
\text { - Interventions to increase cultural competence need to } \\
\text { include a diversity of voices and be community-led }\end{array}$ \\
\hline
\end{tabular}

